\title{
Some Bounds on the Sensitivity of Human Population Dynamics to the Effects of Greenhouse-Gas Reduction of Land Productivity
}

\author{
Jack K. Horner ${ }^{1}$ \\ ${ }^{1}$ Independent Researcher, USA \\ Correspondence: Jack K. Horner, 2130 Owens Lane, Lawrence KS, 66046, USA. Tel: 1-785-424-7579. E-mail: \\ jhorner@cybermesa.com
}

Received: August 29, 2019

Accepted: September 29, 2019

Online Published: November 28, 2019

doi:10.5539/jsd.v12n6p13

URL: https://doi.org/10.5539/jsd.v12n6p13

\begin{abstract}
The 7 August 2019 IPCC special report on land and climate change predicts that the average global temperature will rise more than 1.5 C if human production of greenhouse gases (GHGs) continues at the 2019 rate to 2030, significantly compromising land productivity and the world food supply. Given a relationship between GHGs and land productivity, the World3 simulator can help to bound estimates of the sensitivity of human population dynamics to GHG reduction of land productivity. World3 projects that in the worst case the peak size of the human population could be reduced by $4 \%-37 \%$ by GHG reduction of land productivity, compared to World3's "benchmark scenarios", during calendar years 1900-2100. In particular, World3's "business-as-usual" (BAU) scenario implies that in the worst case the peak size of the human population would be reduced by $\sim 20 \%$ by reduction of land productivity. This BAU-specific result is consistent, to within a factor of two, with $\mathrm{GHG} /$ wheat-productivity relations described in the literature.
\end{abstract}

Keywords: land productivity, climate change, greenhouse gases, human population dynamics

\section{Introduction}

The 7 August 2019 IPCC special report on land and climate change predicts that the average global temperature will rise more than $1.5 \mathrm{C}$ if human production of greenhouse gases (GHGs) continues at the 2019 rate (mass GHG per capita per unit time) to 2030. This temperature rise, the report states, will significantly compromise land productivity (Note 1), threatening the world food supply (IPCC 2019, Section A).

A fundamental question in IPCC 2019 is how we should model the relationship between GHGs and land productivity (which can strongly affect human population dynamics). In the absence of any other considerations, one might suppose that human population dynamics, particularly human population size, varies linearly with GHG (Note 2). Such a model is mathematically simple, but is inadequate as a basis for policy guidance for at least the following reasons:

i. GHGs affect climate change, and GHG-induced climate change is neither spatially nor temporally uniform enough (IPCC 2014) to sustain the assumption of linearity between GHG and land productivity.

ii. Population dynamics can be strongly nonlinear in agricultural, capital, and non-renewable resources (FAO 2019).

In order to assess the relationship between the land-productivity-loss effect of GHGs on human population dynamics, therefore, we need a model that embraces (i)-(ii) and whose behavior is reasonably well understood. The World3 simulator (Meadows et al. 1972b; Cellier 2008; Cellier 2019; Wolfram 2019a) models, at a high level, the dynamical interaction of world population, pollution, agriculture, capital, and non-renewable resources. World3's behavior, furthermore, is reasonably well understood (Turner 2014). Thus, given a relationship between GHGs and land productivity, it is reasonable to hypothesize that World 3 could help to bound estimates of the sensitivity of human population dynamics to GHG reduction of land productivity.

Using World 3 to help bound estimates of the sensitivity of human population dynamics to GHGs has at least one potential limitation. It might be the case that World 3 cannot accommodate the full range of significant effects GHGs could have on land productivity. For example, it might be the case that the effects of GHGs on land productivity are at least twice what World 3 can represent. If so, using World 3 to help bound estimates of the 
effect of GHG-induced land productivity loss on human population dynamics could cause us to seriously misestimate those effects.

Though well taken, it should be noted that this kind of concern applies to any effort to assess the effect of GHG-induced land productivity loss on human population dynamics.

\subsection{Brief history of World 3}

World3 evolved from the Club of Rome's "Limits to Growth" project (Meadows et al. 1972a) in the early 1970s. The objectives of the Limits to Growth project were to determine whether systems analysis techniques developed by Jay Forrester and colleagues at MIT "could provide new perspectives on the interlocking complex of costs and benefits inherent in continued physical growth on a finite planet" (Meadows et al. 1972b, vii).

World2, the immediate predecessor of World3, was written in DYNAMO (Pugh 1963) and was batch-oriented. By 2004, World3 had been ported to the STELLA modeling language (Richmond 2013). Cellier 2019, the version of World 3 used in this paper, is François Cellier's re-engineering (circa 2008) of the 2004 (STELLA) version of World3 to the Modelica (Open Modelica 2019; The Modelica Organization 2019) simulation language under the SystemModeler (Wolfram 2019a) simulation framework ([7]), which can be executed interactively or invoked from Mathematica (Wolfram 2019b). The combined Mathematica and SystemModeler framework makes World3 extensible (i.e, the framework provides read and write access to World3's data structures, model-execution control, extensive visualization functionality, and support ports of applications written in the Mathematica framework to the $\mathrm{C}++$ language (Note 3)).

In the first few years of its existence, the Limits to Growth family of world dynamics simulators was extensively criticized (Simon and Kahn 1984; Simon 1996; Cole et al. 1973). More recent reassessments (Turner 2008; Turner 2014; Randers 2012; Nørgård, Peet, and Ragnarsdóttir 2010), however, argue that from 1980 to the present, World3 (especially World3's Benchmark Scenario 1; see Section 1.3 of this paper) has predicted the actual evolution of the world-state remarkably well.

\subsection{High-level structure of World3}

Software engineering distinguishes a purely conceptual representation of the structure a software system $\mathrm{S}$ from a representation of the structure of a physical implementation of S. In the vocabulary of software engineering, a purely conceptual representation of $\mathrm{S}$ is called a logical representation of $\mathrm{S}$. A representation of a physical implementation of $\mathrm{S}$ describes how the concepts of the logical representation of $\mathrm{S}$ are realized in specific computer languages (together with hardware and human activities). In general, the mapping between the logical and physical representation of the structure of S can be many-to-many. (See Piccinini 2015 for a critical survey of issues arising from the logical/physical distinction.)

To close approximation, the theory and logical design (Boehm 1981, Section 5.4; Boehm et al 2000, 312-313) of World 3 can be found in Meadows et al. 1972b. Much of the detailed physical design (Boehm 1981, Section 5.4; Boehm et al. 2000, 312-313) of Cellier 2019 can be found in the online documentation that accompanies Cellier 2019.

By design fiat, the state variables of the logical structure of World 3 are population, pollution, agriculture, capital, and non-renewable resources. In World3, these variables are interdependent. Figure 1 shows a Level 1 dataflow diagram (DeMarco 1978) of the logical structure of World3. Note that there is a natural one-to-one correspondence between the state variables of the simulator and the processes in the diagram (Note 4). 


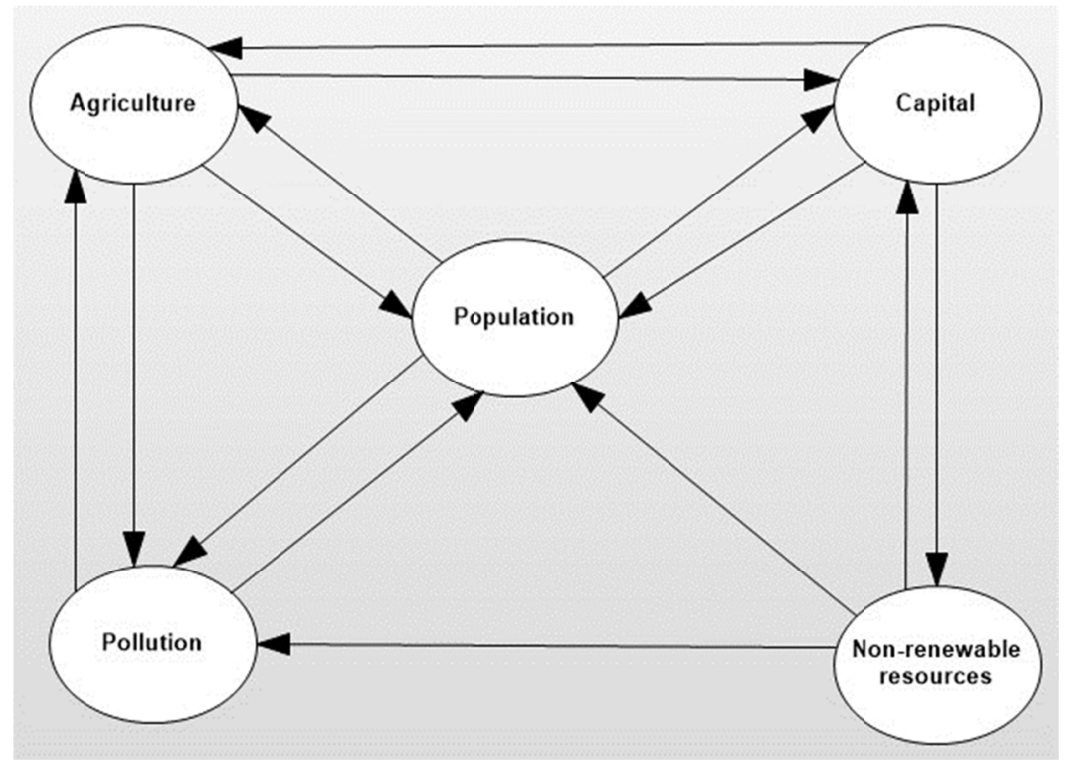

Figure 1. A Level 1 dataflow diagram (DeMarco 1978) of World3. An ellipse represents a process. An arrow represents data flowing from the process at the tail of the arrow to the process at the head of the arrow

The logical structure of World 3 can also be cast in object-oriented terms. In that idiom there is a one-to-one correspondence between the state variables of World 3 and its highest-level logical objects (Rumbaugh, Jacobson, and Booch 1999, 360; Smith 1996) (Note 5). The resulting object-diagram is highly similar to Figure 1, with objects substituted for the processes and object-relations substituted for dataflow arrows (see Rumbaugh, Jacobson, and Booch 1999 for a general account of how dataflow- and object-diagrams are related).

As built, the high-level physical decomposition of Cellier 2019 is more fine-grained than the structure shown in Figure 1 and the "sector" structure of Meadows et al. 1972b (whose network topology is isomorphic to the topology of the network shown in Figure 1). See Cellier 2008 for rationale for these differences.

\subsection{The World3 Benchmark Scenarios}

Meadows, Randers, and Meadows 2004 describe, at a high level, nine World3 scenarios that span regimes ranging from continuing the practices and policies of the 20th century, to a sequence of scenarios that increasingly diverges from the reference scenario through increasing:
a. birth control and pollution controls
b. industrial and agricultural investment
c. food production technology
d. resource conservation practices
e. resource extraction efficiency

For the purposes of this paper, I will call these "the World3 Benchmark Scenarios", or more briefly, "the (nine) Benchmark Scenarios" (Note 6). Collectively, the Benchmark Scenarios provide a de facto baseline for analyzing the sensitivity of World3 to a wide range of variation in World3 parameters (Note 7). By default, the duration of each Benchmark Scenario spans simulated calendar years $1900-2100$ (Note 8). Here is a brief description of the trajectories produced by the Benchmark Scenarios (details of these scenarios can be found in Meadows, Randers, and Meadows 2004; Cellier 2019).

Scenario 1 (the "reference", or "business-as-usual" (BAU), scenario; (Meadows, Randers, and Meadows 2004, pp. 168-171). In Scenario 1, human practices and policies continue without significant deviation from the those followed during most of the 20th century. As a result, population and production increases until growth is halted by increasingly inaccessible resources. Increasing investment is required to maintain resource flows. That investment, which must be re-directed from other sectors of the economy, leads to declining output of both industrial goods and services. The decline of industrial goods and services causes a reduction in the food supply and in health services, thereby decreasing life expectancy, resulting in population "collapse" (a 50\% reduction of population size in $\sim 50$ years) beginning calendar year 2040 . 
Scenario 2 (Meadows, Randers, and Meadows 2004, pp. 172-174). In this scenario, the nonrenewable resources assumed in Scenario 1 are doubled. Scenario 2 further postulates that advances in resource extraction technology postpone the onset of increasing extraction costs, thus allowing industry to grow 20 years longer than in Scenario 1. But as a consequence, pollution levels rise sharply, depressing land yields and requiring massive investments in agricultural recovery. The population finally declines because of food shortages and the health effects of pollution.

Scenario 3 (Meadows, Randers, and Meadows 2004, pp. 210-214). This scenario assumes the nonrenewable resource supply and extraction technologies assumed in Scenario 2. It also assumes increasingly effective pollution control technology that reduces the amount of pollution generated per unit of output by up to 4 percent per year, starting in 2002. This allows much higher welfare for more people after 2040 because of fewer negative effects of pollution. But food production ultimately declines, drawing capital from the industrial sector and triggering a population collapse.

Scenario 4 (Meadows, Randers, and Meadows 2004, pp. 214-216). This scenario adds to the pollution control technology of Scenario 3 and a set of technologies that greatly increase the food yield per unit of land. As a consequence, agricultural activities sharply increase the land loss rate. This scenario ultimately leads to a population collapse.

Scenario 5 (Meadows, Randers, and Meadows 2004, pp. 216-218). This scenario assumes more accessible nonrenewable resources, a better land-preservation technology than Scenario 4, and the pollution-reducing technology of Scenario 4. This only slightly postpones the population collapse to near the end of the 21 st century.

Scenario 6 (Meadows, Randers, and Meadows 2004, pp. 218-220). This scenario assumes the world develops even more powerful pollution abatement and land protection than Scenario 5, and further assumes conservation of nonrenewable resources. All these technologies have costs and take 20 years to be fully implemented. In combination, they yield a fairly large and prosperous population until the accumulated cost of the technologies becomes unsustainable, ending in a population collapse.

Scenario 7 (Meadows, Randers, and Meadows 2004, pp. 238-241). This scenario assumes that after 2002 all families are limited to two children. Because of the age-structure momentum, however, the population continues to grow for another generation. The slower population growth permits industrial output to rise, until it is stopped by the cost of dealing with rising pollution (as in Scenario 2).

Scenario 8 (Meadows, Randers, and Meadows 2004, pp. 241-244). This scenario assumes that after 2002 families are limited to two children. The scenario sets a fixed goal for industrial output per capita. As a result, there is a "golden period" of fairly high human welfare between 2020 and 2040. But rising pollution increasingly stresses agricultural resources. Per capita food production falls, eventually degrading life expectancy and population.

Scenario 9 (Meadows, Randers, and Meadows 2004, pp. 244-247). In this scenario, population and industrial output are limited as in Scenario 8. In addition, technologies are added to aggressively abate pollution, conserve resources, increase land yield, and protect agricultural land. As a consequence, the planet's 8 billion people enjoy a high standard of living, and the human ecological footprint continuously declines.

Of Scenarios 1 - 9, only in Scenario 9 is the human population sustainable past calendar year 2100 (Note 9).

\section{Method}

\subsection{Selection of Parameters to Vary}

Two criteria of adequacy must be satisfied in order to evaluate the sensitivity of a quantity, Y, to another quantity, $\mathrm{X}$, in a given simulation/model $\mathrm{M}$. Assume $\mathrm{X}^{\prime}$ is a proxy for $\mathrm{X}$. Then

A1. In M, we vary $\mathrm{X}\left(\mathrm{X}^{\prime}\right)$ and observe the effect of that variation on $\mathrm{Y}$.

A2. The values of all independent variables and parameters in $M$ other than $\mathrm{X}\left(\mathrm{X}^{\prime}\right)$ are kept constant.

Note that when "sensitivity analysis" is used in the sense of A1-A2, the analysis is not concerned with whether M "correctly" models the world per se. The analysis is instead concerned with the question how, within M, Y varies with $\mathrm{X}\left(\mathrm{X}^{\prime}\right)$. How that sensitivity maps to the world external to $\mathrm{M}$ involves "validation" questions (i.e., conformance of $\mathrm{M}$ to the world $\mathrm{M}$ is intended to model) that are briefly mentioned in Section 4 of this paper (Note 10).

World3 does not explicitly model GHGs or climate change. The simulator does, however, model the effect of 
loss of land productivity on human population dynamics in ways that satisfy A1-A2. Thus, given a relationship between GHGs and land productivity, World 3 can help to bound estimates of the sensitivity of human population dynamics to land-productivity-related effects of GHGs. More specifically, we can use World 3 to help bound estimates of the effect of GHG-related loss of land productivity on human population dynamics by assessing the sensitivity of human population dynamics to land productivity within World3.

In World3, the term "land yield" means land productivity as a function of the use of fertilizer, pesticides, and machinery. In World3, in contrast, the term "land fertility" refers to intrinsic ability of the soil to produce food without modern agricultural practices such as the use of fertilizer, pesticides, and machinery (Meadows et al. 1972b, 259). Note that both "land yield" and "land fertility" in the sense of World 3 are special cases of "land productivity" as defined in Section 1.

Within World3 there are only two (Note 11) (table-defined) parameters, Pollution_Dynamics1.P_Yield_Mlt_Air_Poll ("land yield multiplier due to air pollution"), and Land_Fert_Degr_ Rt ("land fertility degradation rate multiplier"), that can be used unambiguously to simulate the sensitivity of human population dynamics to loss of land yield, and land fertility, respectively, regardless of the cause (such as GHGs). In World3, Pollution_Dynamics1.P_Yield_Mlt_Air_Poll modifies only land yield directly; Land_Fert_Degr_Rt modifies only land fertility directly.

The parameter name "Pollution_Dynamics1.P_Yield_Mlt_Air_Poll" suggests that it concerns air pollution per se. That interpretation of the parameter, however, is not intrinsically limited by the World 3 software as such to air pollution. In a sensitivity analysis (though not in a validation task), this parameter could be regarded as any quantity that is (i) a function of pollution, and (ii) affects land yield, provided that this interpretation is uniformly applied to World3. As a result, use we can use Pollution_Dynamics1.P_Yield_Mlt_Air_Poll as a proxy for any effect on land productivity. For the same reasons, in a sensitivity analysis the parameter "Land_Fert_Degr_Rt" can be regarded as a parameter that affects land productivity and satisfies (i) and (ii).

The alternative within the World3 idiom to expanding the interpretation of Pollution_Dynamics1.P_Yield_Mlt_Air_Poll and Land_Fert_Degr_Rt to be proxies for the effect of climate change on land yield/fertility requires introducing additional parameters dedicated to the effect of climate change per se on yield and land fertility. There are tradeoffs between introducing those complexities on the one hand vs. expanding -- where possible -- the semantics of the parameters mentioned above. It could be argued, for example, that re-purposing the indicated parameters "overloads" the intended semantics of the parameters. All other considerations being the same, semantic overloading of program elements can increase software and conceptual complexity and thereby increase the risk of programming or usage errors (see, for example, Ullman 1988, esp. Chap. 7; Aho, Hopcroft, and Ullman 1983, esp. Section 1.6; Booch and Bryan 1993; Parnas 1972). Against this, it can be argued that at least some kinds of semantic overloading allow us to aggregate similar items better (Note 12) than alternative approaches; indeed, some modern programming languages (e.g., ISO/IEC 2017; MITRE Corporation 2000) have mechanisms to regiment such overloading. In any case, this study varies World3's Pollution_Dynamics1.P_Yield_Mlt_Air_Poll and Land_Fert_Degr_Rt parameters to help bound the effects that (any, including GHG-induced) land-productivity loss could have on human population dynamics in World3.

\subsubsection{Modeling Land Yield Loss due to "Air Pollution" (Used as a Proxy for GHGs)}

In the World3 software, two tables, Pollution_Dynamics1.P_Yield_Mlt_Air_Poll_1 and Pollution_Dynamics1.P_Yield_Mlt_Air_Poll_2, define the effect of "air" pollution on land yield. The values of this parameter are defined as a function of IOC/IO70, where IOC is current Industrial Output and IO70 is Industrial Output in 1970 (Note 13). These tables are initialized as shown in Figure 2. A value ("yval") of 1.0 for Pollution_Dynamics1.P_Yield_Mlt_Air_Poll_1 or Pollution_Dynamics1.P_Yield_Mlt_Air_Poll_2 means that the effect of air pollution on land yield is "no different" from air pollution effects on land yield in 1970; a yval of the form $0 . n, n=1,2, \ldots$, implies that land yield is $0 . n$ times the value of land yield in 1970, all else being the same.

World3 uses the value of a calendric switch parameter, t $t$ air_poll_time, to determine which of Pollution_Dynamics1.P_Yield_Mlt_Air_Poll_1 or Pollution_Dynamics1.P_Yield_Mlt_Air_Poll_2 defines the parameter. The default value of t_air_poll_time in Scenario 1 is calendar year 4000, well past the time interval defined in the Benchmark Scenarios (1900-2100). If the current scenario time is equal to or less than t_air_poll_time, Pollution_Dynamics1.P_Yield_Mlt_Air_Poll_1 values are in play; else, the values in Pollution_Dynamics1.P_Yield_Mlt_Air_Poll_2 are in play.

Note that in Pollution_Dynamics1.P_Yield_Mlt_Air_Poll_1, the effect of the y_vals is on the whole more severe than in Pollution_Dynamics1.P_Yield_Mlt_Air_Poll_2; in the most extreme case 
(Pollution_Dynamics1.P_Yield_Mlt_Air_Poll_1.y_vals[4]) air pollution decreases land yield to 0.4 of nominal, i.e., to 0.4 of the land yield when air pollution is at its 1970 level $(\mathrm{IOC} / \mathrm{IO} 70=1)$.

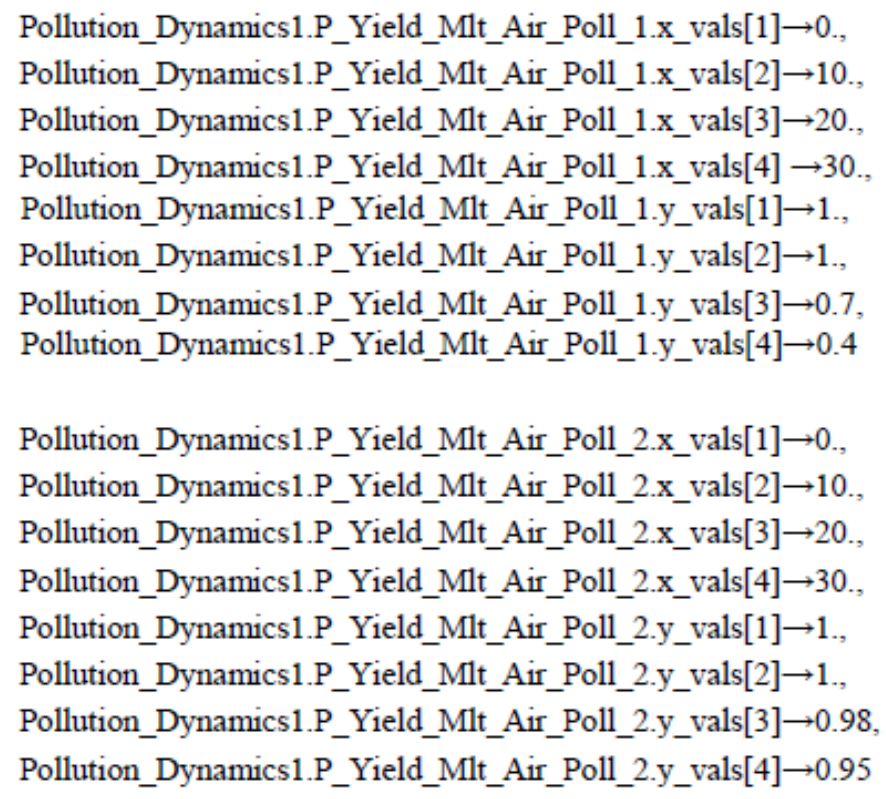

Figure 2. World3 tables Pollution_Dynamics1.P_Yield_Mlt_Air_Poll_1 and

Pollution_Dynamics1.P_Yield_Mlt_Air_Poll_2 in Scenario 1, with default values. The xvals are IOC/IO70, where IOC is current industrial output (as computed by the simulator) normalized to industrial output in calendar year 1970 (IO70). For example, the combination of

"Pollution_Dynamics1.P_Yield_Mlt_Air_Poll_1.x_vals[3] $\rightarrow 20$."

and "Pollution_Dynamics1.P_Yield_Mlt_Air_Poll_1.y_vals[3] $\rightarrow 0.7$ " means that if table

Pollution_Dynamics1.P_Yield_Mlt_Air_Poll_1 values are in effect, and if the current Industrial Output is 20 times the Industrial Output of 1970, then the multiplier for the effect of air pollution on land yield is 0.7 (i.e., all else being the same, the land yield is $70 \%$ of the 1970 value of land yield.)

For each of Benchmark Scenarios 1-9, each of the five experiments described below was executed under Wolfram 2019a running under Mathematica (Wolfram 2019b) with Dynamic Updating enabled, all under Windows 10, on a Dell Inspiron 545 desktop containing an Intel Q8200 quadprocessor clocked at $2.33 \mathrm{GHz}$ and $8 \mathrm{~GB}$ of physical memory. Microsoft $\mathrm{C}++$ Visual Studio provided the software development and build environments required by Wolfram 2019a. The variables shown in Figure 3 were plotted (as a function of time).
1. Population
2. Land Yield
3. Life_Expectancy
4. Human_Welfare_Index
5. Human_Ecological_Footprint
6. Food_Production_Per_Capita
7. Food_Production, Industrial_Production (on same set of axes)
8. Services_Output_Per_Capita, Industrial_Output_Per_Capita (on same set of axes)
9. Persistent_Pollution_Index
10. Non-Renewable_Resources_Remaining

Figure 3. World 3 variables (see Meadows et al. 1972b and Cellier 2019 for definitions) plotted in this study

Experiment 1. The baseline Benchmark Scenario was executed as is (which assumes the values defined in Figure 1 for Pollution_Dynamics1.P_Yield_Mlt_Air_Poll_1 ).

Experiment 2. The value of variable t_air_poll_time in the baseline Benchmark Scenario was changed to calendar year 2020 (thus switching to the "mitigated-air-pollution" values defined in 
Pollution_Dynamics1.P_Yield_Mlt_Air_Poll_2 at calendar year 2020).

Experiment 3. The value of t_air_poll_time in the baseline Benchmark Scenario was set to calendar year 1970 (thus switching to the "mitigated-air-pollution" values defined in Pollution_Dynamics1.P_Yield_Mlt_Air_Poll_2 at calendar year 1970).

Experiment 4. The value of t_air_poll_time was defaulted to calendar year 4000. The values of Pollution_Dynamics1.P_Yield_Mlt_Air_Poll_1.y_vals in the baseline Benchmark Scenario were changed to those shown in Figure 4:

Pollution_Dynamics1.P_Yield_Mlt_Air_Poll_1.y_vals[1] $\rightarrow 0.7$,
Pollution_Dynamics1.P_Yield_Mlt_Air_Poll_1.y_vals[2] $\rightarrow 0.5$,
Pollution_Dynamics1.P_Yield_Mlt_Air_Poll_1.y_vals[3] $\rightarrow 0.3$,
Pollution_Dynamics1.P_Yield_Mlt_Air_Poll_1.y_vals[4] $\rightarrow 0.1$

Figure 4. Pollution_Dynamics1.P_Yield_Mlt_Air_Poll_1.y_vals for Experiment 4

Experiment 5. The value of t_air_poll_time was defaulted to calendar year 4000. The values of Pollution_Dynamics1.P_Yield_Mlt_Air_Poll_1.y_vals in the given Benchmark Scenario were changed to those shown in Figure .

Pollution_Dynamics1.P_Yield_Mlt_Air_Poll_1.y_vals[1] $\rightarrow 0.7$,
Pollution_Dynamics1.P_Yield_Mlt_Air_Poll_1.y_vals[2] $\rightarrow 0.1$,
Pollution_Dynamics1.P_Yield_Mlt_Air_Poll_1.y_vals[3] $\rightarrow 0.1$,
Pollution_Dynamics1.P_Yield_Mlt_Air_Poll_1.y_vals[4] $\rightarrow 0.1$

Figure 5. Pollution_Dynamics1.P_Yield_Mlt_Air_Poll_1.y_vals for Experiment 5

\subsubsection{Modeling Land Fertility Loss due to Pollution}

In World3, the effect of "persistent pollution" on land fertility degradation rate is modeled as a (table-defined) function of the "persistent pollution index", where the persistent pollution index is defined as persistent pollution normalized to the value of persistent pollution in 1970. This table is initialized as shown in Figure 6. 


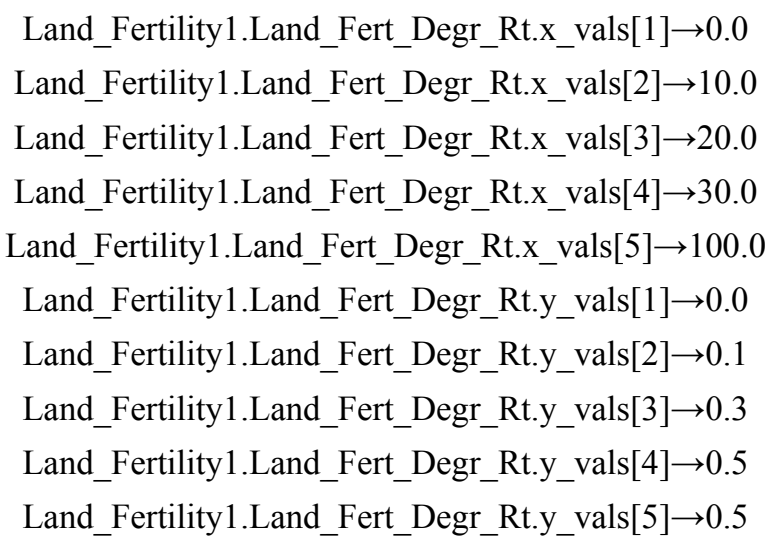

Figure 6. Table Land_Fertility1.Land_Fert_Deg_Rt, with default values. A value of 0.0 for

Land_Fertility1.Land_Fert_Deg_Rt of 0.0 signifies that the pollution effect on land fertility degradation rate "no different" from pollution effects on the land fertility degradation rate in 1970; a value $0 . \mathrm{n}$ strictly between 0 and

1 implies that the land fertility degradation rate, is $1 . n$ times the land fertility degradation rate in 1970 . For example, if the persistent pollution index is 20 times that of 1970

(Land_Fertility1.Land_Fert_Degr_Rt.x_vals[3] $\rightarrow 20.0$ ), the resulting Land_Fertility1.Land_Fert_Deg_Rt (Land_Fertility1.Land_Fert_Degr_Rt.y_vals[3] $\rightarrow 0.3$ ), i.e., the land fertility degradation rate is 1.3 times what it was in 1970

For each of Benchmark Scenarios 1-9, the Land Fertility Degradation Rate yvals were changed as shown in Figure 7, and the results were executed on the platform described in Section 2. The variables shown in Figure 3 were plotted.

$$
\begin{aligned}
& \text { Land_Fertility1.Land_Fert_Degr_Rt.y_vals[1] } \rightarrow 0.0 \\
& \text { Land_Fertility1.Land_Fert_Degr_Rt.y_vals[2] } \rightarrow 0.3 \\
& \text { Land_Fertility1.Land_Fert_Degr_Rt.y_vals[3] } \rightarrow 0.5 \\
& \text { Land_Fertility1.Land_Fert_Degr_Rt.y_vals[4] } \rightarrow 0.7 \\
& \text { Land_Fertility1.Land_Fert_Degr_Rt.y_vals[5] } \rightarrow 0.7
\end{aligned}
$$

Figure 7. Modified values of Land Fertility Degradation Rates. (These values represent, to one significant figure, the largest Land_Fertility1.Land_Fert_Degr_Rt.y_vals consistent with World3's internal smoothing functions, integration algorithms, and explicit limits on the values of its parameters and variables.)

Because of memory-management limitations of the platform described in Section 2, I distributed the computations in the study across 18 Mathematica "notebook" files, one file for each line in Figure 8 for Appendices 1-45, and one file each of Appendices 46-54 as shown in Figure 8. 


\begin{tabular}{cl}
\hline Appendices 1-5: & Experiments 1-5 on Benchmark Scenario 1 \\
Appendices 6-10: & Experiments 1-5 on Benchmark Scenario 2 \\
Appendices 11-15: & Experiments 1-5 on Benchmark Scenario 3 \\
Appendices 16-20: & Experiments 1-5 on Benchmark Scenario 4 \\
Appendices 21-25: & Experiments 1-5 on Benchmark Scenario 5 \\
Appendices 26-30: & Experiments 1-5 on Benchmark Scenario 6 \\
Appendices 31-35: & Experiments 1-5 on Benchmark Scenario 7 \\
Appendices 36-40: & Experiments 1-5 on Benchmark Scenario 8 \\
Appendices 41-45: & Experiments 1-5 on Benchmark Scenario 9
\end{tabular}

Figure 8. Cross-reference of Benchmark Scenarios/Experiments and Appendices

Each execution run was saved both as a Mathematica "notebook" (executable) file, and as a PDF file. The resulting PDF files were concatenated under PDF Shaper (Burnaware 2019). The Appendices ( $\sim 370$ pages) can be found online at http://jkhorner.com/POPULATION_DYNAMICS/allmerged_paginated.pdf.

\section{Results}

The Appendices provide an expansive picture of the sensitivity of the variables in Figure 3 to the conditions described in Experiments 1-5 (on the Benchmark Scenarios). Tables 1-4 summarize the effects, in World3, of loss of land productivity on some population-size metrics.

Table 1. Some World3 population-size metrics for Benchmark Scenario 1

\begin{tabular}{|c|c|c|c|c|}
\hline $\begin{array}{l}\text { Base } \\
\text { Scenario }\end{array}$ & $\begin{array}{l}\text { Parameters changed (relative to base } \\
\text { scenario) }\end{array}$ & $\begin{array}{l}\text { Population } \\
\text { (billion) }\end{array}$ & Maximum & $\begin{array}{l}\text { Percentage change of population max. compared to } \\
\text { base scenario }\end{array}$ \\
\hline Benchmark 1 & none & 8.4 & & 0 \\
\hline Benchmark 1 & Figure 4 & 6.8 & & -19 \\
\hline Benchmark 1 & Figure 5 & 6.4 & & -24 \\
\hline Benchmark 1 & t_air_poll_time $=1970$ & 8.4 & & 0 \\
\hline Benchmark 1 & t_air_poll_time $=2020$ & 8.4 & & 0 \\
\hline Benchmark 1 & Figure 6 & 7.6 & & -10 \\
\hline
\end{tabular}

Note. The population minimum in all scenarios is 1.6 billion; the year of population minimum, 1900. Maximum and minimum population values were extracted by the software shown in the Appendices. The time of maximum population (not shown here) was obtained by interactively querying plots in the Appendices using the Mathematica function "Get Coordinates". Values in rightmost column of the table are rounded. 
Table 2. Some World3 population-size metrics as a function of Benchmark Scenarios 2-4

\begin{tabular}{|c|c|c|c|c|}
\hline $\begin{array}{l}\text { Base } \\
\text { Scenario }\end{array}$ & $\begin{array}{l}\text { Parameters changed (relative to base } \\
\text { scenario) }\end{array}$ & $\begin{array}{l}\text { Population } \\
\text { (billion) }\end{array}$ & Maximum & $\begin{array}{l}\text { Percentage change of population max. compared to } \\
\text { base scenario }\end{array}$ \\
\hline Benchmark 2 & none & 9.2 & & 0 \\
\hline Benchmark 2 & Figure 4 & 7.1 & & -23 \\
\hline Benchmark 2 & Figure 5 & 6.6 & & -28 \\
\hline Benchmark 2 & t_air_poll_time $=1970$ & 9.2 & & 0 \\
\hline Benchmark 2 & t_air_poll_time $=2020$ & 9.2 & & 0 \\
\hline Benchmark 2 & Figure 6 & 7.8 & & -15 \\
\hline Benchmark 3 & none & 9.3 & & 0 \\
\hline Benchmark 3 & Figure 4 & 7.8 & & -15 \\
\hline Benchmark 3 & Figure 5 & 7.0 & & -25 \\
\hline Benchmark 3 & t_air_poll_time $=1970$ & 9.3 & & 0 \\
\hline Benchmark 3 & t_air_poll_time $=2020$ & 9.3 & & 0 \\
\hline Benchmark 3 & Figure 6 & 8.2 & & -12 \\
\hline Benchmark 4 & none & 9.5 & & 0 \\
\hline Benchmark 4 & Figure 4 & 8.1 & & -15 \\
\hline Benchmark 4 & Figure 5 & 7.5 & & -21 \\
\hline Benchmark 4 & t_air_poll_time $=1970$ & 9.5 & & 0 \\
\hline Benchmark 4 & t_air_poll_time $=2020$ & 9.5 & & 0 \\
\hline Benchmark 4 & Figure 6 & 9.1 & & -4 \\
\hline
\end{tabular}

Table 3. Some World3 population-size metrics as a function of Benchmark Scenarios 5-8

\begin{tabular}{|c|c|c|c|c|}
\hline $\begin{array}{l}\text { Base } \\
\text { Scenario }\end{array}$ & $\begin{array}{l}\text { Parameters changed (relative to base } \\
\text { scenario) }\end{array}$ & $\begin{array}{l}\text { Population } \\
\text { (billion) }\end{array}$ & Maximum & $\begin{array}{l}\text { Percentage change of population max. compared to } \\
\text { base scenario }\end{array}$ \\
\hline Benchmark 5 & none & 10 & & 0 \\
\hline Benchmark 5 & Figure 4 & 8.8 & & -12 \\
\hline Benchmark 5 & Figure 5 & 7.8 & & -22 \\
\hline Benchmark 5 & t_air_poll_time $=1970$ & 10 & & 0 \\
\hline Benchmark 5 & t_air_poll_time $=2020$ & 10 & & 0 \\
\hline Benchmark 5 & Figure 6 & 10 & & 0 \\
\hline Benchmark 6 & none & 10 & & 0 \\
\hline Benchmark 6 & Figure 4 & 8.3 & & -17 \\
\hline Benchmark 6 & Figure 5 & 7.5 & & -25 \\
\hline Benchmark 6 & t_air_poll_time $=1970$ & 10 & & 0 \\
\hline Benchmark 6 & t_air_poll_time $=2020$ & 10 & & 0 \\
\hline Benchmark 6 & Figure 6 & 9.1 & & -9 \\
\hline
\end{tabular}




\begin{tabular}{llll}
\hline Benchmark 7 & Figure 4 (Note 14) & ND & ND \\
Benchmark 7 & Figure 5 & 5 & -37 \\
Benchmark 7 & t_air_poll_time $=1970$ & 7.9 & 0 \\
Benchmark 7 & t_air_poll_time $=2020$ & 7.9 & 0 \\
Benchmark 7 & Figure 6 & 6.9 & -14 \\
\hline Benchmark 8 & none & 7.8 & 0 \\
Benchmark 8 & Figure 4 & 5.5 & -29 \\
Benchmark 8 & Figure 5 & 5.1 & -35 \\
Benchmark 8 & t_air_poll_time $=1970$ & 7.8 & 0 \\
Benchmark 8 & t_air_poll_time $=2020$ & 7.8 & 0 \\
Benchmark 8 & Figure 6 & 7.0 & -11 \\
\hline
\end{tabular}

Note. The population minimum in all scenarios is 1.6 billion; the year of population minimum, 1900. Maximum and minimum population values were extracted by the software shown in the Appendices. The time of maximum population (not shown here) was obtained by interactively querying plots in the Appendices using the Mathematica function "Get Coordinates". Values in rightmost column of the table are rounded.

Table 4. Some World3 population-size metrics for Benchmark Scenario 9

\begin{tabular}{|c|c|c|c|c|}
\hline $\begin{array}{l}\text { Base } \\
\text { Scenario }\end{array}$ & $\begin{array}{l}\text { Parameters changed (relative to base } \\
\text { scenario) }\end{array}$ & $\begin{array}{l}\text { Population } \\
\text { (billion) }\end{array}$ & Maximum & $\begin{array}{l}\text { Percentage change of population max. compared to } \\
\text { base scenario }\end{array}$ \\
\hline Benchmark 9 & none & 8.5 & & 0 \\
\hline Benchmark 9 & Figure 4 & 5.8 & & -32 \\
\hline Benchmark 9 & Figure 5 & 5.6 & & -35 \\
\hline Benchmark 9 & t_air_poll_time $=1970$ & 8.5 & & 0 \\
\hline Benchmark 9 & t_air_poll_time $=2020$ & 8.5 & & 0 \\
\hline Benchmark 9 & Figure 6 & 7.8 & & -8 \\
\hline
\end{tabular}

Note. The population minimum in all scenarios is 1.6 billion; the year of population minimum, 1900. Maximum and minimum population values were extracted by the software shown in the Appendices. The time of maximum population (not shown here) was obtained by interactively querying plots in the Appendices using the Mathematica function "Get Coordinates". Values in rightmost column of the table are rounded.

Each of the notebooks for Appendices 1-45 executed in 20 minutes on the platform described in Section 2.0; each of the notebooks for Appendices 46-54 on the same platform executed in $\sim 5$ minutes.

\section{Discussion}

The results in Section 3 show that in the scenarios described in Section 2, World3 projects that (in the worst case) the peak size of the human population would be reduced by $19 \%-37 \%$ by the effects of land yield loss due to the modifications shown in Figures 4 and 5, depending on scenario, compared to the peak human population size in the unmodified World3 Benchmark scenarios. The simulator projects that (in the worst case) the peak size of the human population would be reduced by $4 \%-15 \%$, depending on scenario, due to the modifications shown in Figure 6, compared to the peak human population size in the unmodified World3 Benchmark scenarios.

Experiments 1-5 probe World3's sensitivity to a range of values of Pollution_Dynamics1.P_Yield_Mult_Air_Poll without regard to whether these values correspond to anything in the actual trajectory of the world system. If World 3 is to be used to help estimate the sensitivity of human population dynamics to loss of land productivity due to GHGs in the actual world system, we need at least a rough approximation of the GHG/land_productivity relationship in the actual world system. That relationship is not uniform across GHG and temperature scaling. For increases of $<2 \mathrm{C}$ above the 2019 average global temperature, the relationship is plausibly linear. (For increases of $>5 \mathrm{C}$ above the 2019 average global temperature, highly nonlinear climate changes including widespread changes in precipitation patterns are likely to have strong nonlinear effects on land productivity (IPCC 2019, Chap. 2) and thus lie outside World3's scope.) 
Liu et al. 2016 and Asseng et al. 2015 have estimated that a $1-5$ C increase in temperature above 2015/2016 values will result in a loss of $\sim 5 \%$ of wheat production, per degree Celsius increase. If we adopt this "wheat"-oriented temperature-land-productivity-loss relationship as a proxy for land productivity, and assume that relationship is linear, a $2 \mathrm{C}$ increase in temperature above $2015 / 2016$ values would result in a $(2 \times 5 \%=) \sim 10 \%$ loss of land productivity, corresponding to a nominal value of $(1-0.1=) \quad 0.9$ for Pollution_Dynamics1.P_Yield_Mult_Air_Poll. 0.9 is well above the largest yval (0.7) in Figure 4. In that case, we would expect that a linearized effect of a $2 \mathrm{C}$ temperature increase on population size to be smaller than what is shown in Table 1 for Figure 4.

Tables 1 shows that Benchmark Scenario 1 ("business-as-usual"), modified as noted in Figure 4, implies that erosion of land productivity will reduce the peak size of the human population by $\sim 20 \%$. Subject to all the caveats and assumptions above, therefore, the World 3 prediction of the sensitivity of population size to GHGs is consistent, to within a factor of two, with the linearized extrapolation of the GHG/wheat-production relationship estimated by Liu et al. 2016 and Asseng et al. 2015.

Tables 1-4 show that taken as a group, the population peaks of variants of Scenarios 1-3 are less sensitive to variations in land productivity than the population peak of variants Scenario 9. This result is consistent with the observation (see Meadows, Randers, and Meadows 1974) that the population trajectory is sustainable only if almost all the conditions of unmodified Scenario 9 are satisfied.

Changing (only) the value of $t$ _air_poll_time in any of the Benchmark Scenarios has no effect on the predictions of population peak size, under the conditions simulated, compared to the peak population predicted by the unmodified Benchmark Scenarios.

\section{Acknowledgements}

This work benefited from discussions with Toufiq Siddiqi, who introduced me to Meadows et al. 1972b, to John Symons, and to Dean Gonzalez, whose software-design wizardry was an inspiration to all of us who were privileged to have known him. For any infelicities which remain, I am solely responsible.

\section{References}

Aho, A. V., Hopcroft, J. E., \& Ullman, J. D. (1983). Data Structures and Algorithms. Reading, MA: Addison-Wesley.

Asseng, S. et al. (2015). Rising temperatures reduce global wheat production. Nature Climate Change, 5, 143147. https://doi.org/10.1038/nclimate2470

Boehm, B .W., Abts, C., Brown, A. W., Chulani, S, Clark, B. K., Horowitz, E., ... Steece, B. (2000). Software Cost Estimation with COCOMO II. Upper Saddle River, NJ: Prentice-Hall.

Boehm, B. W. (1981). Software Engineering Economics. Englewood Cliffs, NJ: Prentice-Hall.

Booch, G., \& Bryan, D. (1993). Software Engineering with Ada (3rd ed.). Reading, MA: Addison-Wesley.

Burnaware. (2019). PDF Shaper v9.2. Retrieved from http://www.pdfshaper.com

Cellier, F. E. (2008). World 3 in Modelica: Creating system dynamics models in the Modelica framework. Retrieved April 28, 2019, from https://inf.ethz.ch/personal/cellier/Pubs/World/modelica_08_World3.pdf

Cellier, F. E. (2019). System Dynamics. World Dynamics. World 3. Retrieved March 17, 2019, from https://build.openmodelica.org/Documentation/SystemDynamics.WorldDynamics.World3.html

Cole, H. S. D., Freeman, C., Jahoda, M., \& Pavitt, K. L. R. (Eds.). (1973). Models of Doom: A Critique of the Limits to Growth. New York, NY: Universe Publishing.

DeMarco, T. (1978). Structured Analysis and System Design. New York, NY: Yourdon Press.

Food and Agriculture Organization of the United Nations (FAO). (2019). Food Outlook. Retrieved May 25, 2019, from http://www.fao.org/3/ca4526en/ca4526en.pdf

IEEE. (2011). P1490/D1, May 2011 - IEEE Draft Guide: Adoption of the Project Management Institute (PMI) Standard: A Guide to the Project Management Body of Knowledge (PMBOK Guide - 2008) (4th ed.). IEEE.

Intergovernmental Panel on Climate Change (IPCC). (2014). AR5 Synthesis Report on Climate Change 2014. IPCC.

Intergovernmental Panel on Climate Change. (2019). Land. Special Report on Climate Change, Desertification, Land Degradation, Sustainable Land Management, Food Security, and Greenhouse gas fluxes in Terrestrial Ecosystem. Retrieved August 8, 2019, from https://www.ipcc.ch/srccl-report-download-page/ 
ISO/IEC. (2017). 14882:2017. Programming Languages -- $C++$.

Liu, B. et al. (2016). Similar estimates of temperature impacts on global wheat yield by three independent methods. Nature Climate Change, 6, 1130-1136. https://doi.org/10.1038/nclimate3115

Meadows, D. H., Meadows D. L., Randers J., \& Behrens, W. W., III. (1972). The Limits to Growth. Washington, DC: Potomac Associates.

Meadows, D. H., Randers, J., \& Meadows, D. L. (2004). The Limits to Growth: The 30-Year Update. White River Junction, VT: Chelsea Green.

Meadows, D. L., Behrens, W. W. III, Meadows, D. H., Naill, R. F., Randers, J., \& Zahn, E. K. O. (1972). Dynamics of Growth in a Finite World. Cambridge, MA: Wright-Allen Press.

MITRE Corporation. (2000). Ada Reference Manual. ISO/IEC 8652:1995(E) with COR.1:2000.

Nørgård, J. S., Peet, J., \& Ragnarsdóttir, K. V. (2010). The History of The Limits to Growth. The Solutions Journal, 1(2), 59-63.

OpenModelica Organization. (2019). OpenModelica. Retrieved April 28, 2019, from https://www.openmodelica.org

Parnas, D. L. (1972). On the criteria to be used in decomposing systems into modules. Communications of the ACM, 15(12), 1053-1058. https://doi.org/10.1145/361598.361623

Piccinini, G. (2015). Physical Computation: A Mechanistic Account. Oxford, UK: Oxford University Press. https://doi.org/10.1093/acprof:oso/9780199658855.001.0001

Pugh, A. L. (1963). DYNAMO USER'S MANUAL. Boston, MA: MIT Press.

Randers, J. (2012). 2052: A Global Forecast for the Next Forty Years. White River Junction, VT: Chelsea Green.

Richmond, B. (2013). An Introduction to Systems Thinking, STELLA. Lebanon, NH: ISEE Systems.

Rumbaugh, J., Jacobson, I., \& Booch, G. (1999). The Unified Modeling Language Reference Manual. Reading, MA: Addison Wesley.

Schlaer, S., \& Mellor, S. J. (1992). Object Lifecycles: Modeling the World in States. New York, NY: Yourdon Press.

Simmons, G. F. (2017). Differential Equations with Applications and Historical Notes (3rd ed.). New York, NY: CRC Press.

Simon, J. L. (1996). The Ultimate Resource 2. Princeton, NJ: Princeton University Press.

Simon, J. L., \& Kahn, H. (1984). The Resourceful Earth. Oxford, UK: Basil Blackwell.

Smith, B. C. (1996). On the Origin of Objects. Boston, MA: MIT Press.

The Modelica Association. (2019). Modelica. Retrieved April 28, 2019, from https://www.modelica.org/

Turner, G. M. (2014). Is Global Collapse Imminent? MSSI Research Paper No. 4. Melbourne Sustainable Society Institute. Retrieved August 13, 2019, from https://sustainable.unimelb.edu.au/_data/assets/pdf_file/0005/2763500/MSSI-ResearchPaper-4_Turner_20 14.pdf

Turner, G. M. (2008). A comparison of The Limits to Growth with 30 years of reality. Global Environmental Change, 18, 397-411. https://doi.org/10.1016/j.gloenvcha.2008.05.001

Ullman, J. D. (1988). Principles of Database and Knowledge-Base Systems. Volume I. Rockville, MD: Computer Science Press.

Wolfram Research. (2019a). System Modeler v12.0. Retrieved March 24, 2019, from http://www.wolfram.com/SystemModeler/

Wolfram Research. (2019b). Mathematica v12.0 Home Edition. Retrieved March 15, 2019, from http://www.wolfram.com/Mathematica-home-edition/

\section{Notes}

Note 1. For the purposes of this paper, "land productivity" means "mass of food produced per unit land area per unit time". 
Note 2. IPCC 2019 does not assume a linear relation between GHGs and population dynamics.

Note 3. The combined Mathematica/SystemModeler/World3 framework is characterized as "experimental" by the Mathematica v12 documentation (Wolfram 2019b).

Note 4. Dataflow diagrams do not depict conditionality or temporality.

Note 5. The relationship between state variables and objects can be many-to-many (Shlaer and Mellor 1992, 22; Rumbaugh, Jacobson, and Booch 1999, 48).

Note 6. What scenarios should be subsumed under this name might be debated, but it's clear enough that the community of World 3 users has found the nine used in this paper are a convenient choice. Meadows, Randers, and Meadows 2004 describe a $10^{\text {th }}$ scenario, which is Scenario 9 with the sustainability policies of Scenario 9 introduced 20 years earlier. Cellier 2019 includes a $10^{\text {th }}$ and $11^{\text {th }}$ scenario, neither of which identical to any of Scenarios 1-9. Scenarios 10 and 11 of Cellier 2019, moreover, will not compile on the platform described in Section 2 of this paper.

Note 7. Unless otherwise noted, the term "parameter" in this paper means "a user-settable constant".

Note 8. World 3 projections past 2100 likely lie well outside the calibration range of the simulator.

Note 9. The values of a few initial conditions and parameter values in the Benchmark Scenarios as described Cellier 2019 differ slightly from those in Meadows et al. 1972. These differences are the result of re-calibration of World3 between about 1975 and about 2010. The differences between the projections of the Benchmark Scenarios in Meadows et al. 1972 and the corresponding Benchmark Scenarios in Cellier 2019 that arise from the differences in the initial conditions and parameter values in Meadows et al. 1972 and Cellier 2019 are minor.

Note 10. Following IEEE 2011, I distinguish "verification", which concerns a satisfaction relation between a software system S and its specification, from "validation", which concerns the relationship between the specification and something (naively, the "real world") that is independent of the specification and software.

Note 11. This claim can be confirmed by analyzing the World 3 software. Other World 3 parameters are related to the effects of land yield on population, but each of those parameters has additional effects that, within the domain of the simulator, are not specifically attributable to the effects of land productivity on population.

Note 12. Where "better" must be defined with respect to specific objectives.

Note 13. World 3 assumes that pollution is an increasing, but not linear, function of industrial output.

Note 14. This scenario aborts due an ASSERT failure.

\section{Copyrights}

Copyright for this article is retained by the author(s), with first publication rights granted to the journal.

This is an open-access article distributed under the terms and conditions of the Creative Commons Attribution license (http://creativecommons.org/licenses/by/4.0/). 